\title{
Cartografias militantes
}

Activists Cartographies

Cartografías militantes

\author{
Carolina Cechella Philippi' (iD) 0000-0001-6121-254X \\ 'Unicamp, Colégio Técnico de Limeira, Limeira, SP. Brasil. 13484-431 - \\ sociopedag@cotil.unicamp.br
}

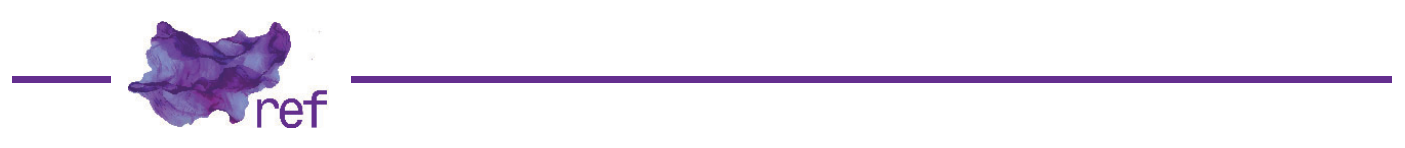

GAGO, Verónica.

A potência feminista ou o desejo de transformar tudo.

Trad. de Igor Peres. São Paulo: Elefante, 2020.

\begin{abstract}
"A potência feminista" é um programa de ação e um artifício à medida que traz, desde o título, o signo do movimento. Nesse sentido, a potência feminista é entendida como uma teoria alternativa do poder (Verónica GAGO, 2020, p. 10), tratando-se "da força do processo protagonizado pelos feminismos nos últimos anos" (GAGO, 2020, p. 291). Esse desenho teórico dá pistas da configuração de produção do livro cuja autora, docente da Universidade de Buenos Aires e da Universidade de San Martin, tem a trajetória acadêmica marcada pela colaboração com os coletivos Situaciones e NiUnaMenos.

Esse movimento é feito por meio da greve como uma lente em dois sentidos - analíitico e prático -, pelos quais é possível pensá-la como "[...] uma ferramenta prática de investigação política e um processo capaz de construir a transversalidade entre corpos, conflitos e territórios" (GAGO, 2020, p. 15).

Essas prerrogativas são aprofundadas no primeiro capítulo, "\#NosotrasParamos: por uma teoria políica da greve feminista" no qual a greve é pensada como "[...] uma nova forma de cartografia prática da política feminista, [um] [...] horizonte prático e perspectiva analítica a partir de lutas [...] que possibilit[am] impulsionar um feminismo popular e antiliberal" (GAGO, 2020, p. 21). É a greve, conforme sua hipótese, a responsável pela tessitura de múltiplas formas de insubordinação (GAGO, 2020, p. 21), permitindo "cartografar [...] as formas de exploração do trabalho, dos territórios e das tramas vitais que se visibilizam e valorizam ao desenvolver uma perspectiva feminista" (GAGO, 2020, p. 25). Além disso, provoca um transbordamento ao acolher realidades de trabalho não assalariado e se converte em um vetor de transversalidade' (GAGO, 2020, p. 26-27).

O movimento de greve, em uma perspectiva feminista, extrapola as espacialidades do trabalho assalariado e torna necessária a reflexão acerca da centralidade do trabalho social, afetivo e de cuidado. Nesse sentido, ela é redimensionada ao questionar-se a respeito do conceito de trabalho patriarcal que relaciona a dignidade laboral ao recebimento de um
\end{abstract}

1 A autora operacionaliza a noção de greve de Rosa Luxemburgo (1970) para apreendê-la em sua transversalidade, sendo entendida como um processo possuidor de um pensamento político (GAGO, 2020, p. 49). 
salário já que "a forma de exploração organizada pelo salário invisibiliza, disciplina e hierarquiza outras formas de exploração" (GAGO, 2020, p. 63).

O capítulo seguinte - "Violências: há uma guerra no e contra o corpo das mulheres?" - operacionaliza a pluralização da definição de violência como forma de permitir um deslocamento da figura totalizante da vítima (GAGO, 2020, p. 72). A autora lança duas perguntas fundamentais: "o que significa produzir formas de autodefesa feminista diante do incremento das violências [...] e o que significaria se o movimento feminista pudesse produzir suas próprias máquinas de justiça?" (GAGO, 2020, p. 72). Verónica Gago defende, então, a hipótese de que hoje "a guerra contra as mulheres, lésbicas, trans e travestis se expressa em quatro circunstâncias que estão na base dos feminicídios" (GAGO, 2020, p. 82). São elas: a violência doméstica como efeito da crise da figura do homem provedor; a organização de novas formas de violência a partir da organização de economias ilegais; a espoliação de terras por parte de transnacionais; a articulação da exploração pela via da financeirização da vida social (GAGO, 2020, p. 83). Como resposta a essas investidas, é proposta a construção de tramas adensadas para proteção e autodefesa pela via da organização de cuidados coletivos.

Já no terceiro capítulo, "Corpo-território: o corpo como campo de batalha", é lançada a hipótese de que a domesticação e a colonização constituem uma relação específica no modo de explorar mão de obra e subordinar territórios (GAGO, 2020, p. 105). Para tanto, utiliza-se da noção de "corpo-território" como forma de desliberalizar o corpo individual e especificar uma continuidade política, produtiva e epistêmica (GAGO, 2020, p. 107). Nesse sentido, "o corpo território possibilita o desacato, a confrontação e a invenção de outros modos de vida [...], [sendo] uma ideia-força que surge de certas lutas mas que tem a potência de migrar, ressoar e compor outros territórios e outras lutas" (GAGO, 2020, p. 110).

Em "Economia feminista: exploração e extração", Verónica Gago reitera a pergunta sobre o diferencial da exploração das mulheres, lésbicas, trans e travestis. Esse questionamento faz pensar no lugar concreto para seu início: a reprodução (GAGO, 2020, p. 143). Trata-se, portanto, de visualizar o conjunto de explorações a partir de uma conflituosidade concreta, entendendo que os corpos feminilizados apresentam uma perspectiva que reformula a análise econômica. É também pela via da economia feminista que se propõe uma nova leitura da obra de Karl Marx, visto que se ele "discute com as teorias neoclássicas para desfetichizar a esfera da circulação, as feministas escavam mais fundo e desfetichizam a esfera de produção. Chegam, assim, ao subsolo da reprodução, [...] [inaugurando] uma verdadeira perspectiva 'de baixo"' (GAGO, 2020, p. 147).

É com a politização da reprodução proposta pela economia feminista que se relaciona a dimensão política das economias populares (GAGO, 2020, p. 154) já que elas envolvem uma dimensão reprodutiva que lhes é central a partir de uma prática política no interior de um cenário de crise. Também pela via das lutas gestadas pelo movimento feminista atual buscase um movimento de coletivização do problema financeiro e de leitura feminista da dívida, reelaborando as noções marxianas de "burguesia" e "meios de produção" (GAGO, 2020, p. 163). Delineia-se, assim, uma leitura própria da noção de trabalho.

A essa leitura se combina o entendimento das assembleias como as cozinhas ${ }^{2}$ das greves por serem, conforme enunciado no quinto capítulo, "um dispositivo situado de inteligência coletiva" (GAGO, 2020, p. 187). São, pois, essas assembleias que produzem a greve como processo político, temporalizando-a. Nelas residem as potências de gestarem um poder de avaliação da situação, uma capacidade estratégica de operar a decisão política e a destreza necessária para concretizá-la. Para além disso, produzem uma nova forma de pensar o tempo político, escapando do binarismo entre reforma e revolução e evocando o que Rosa Luxemburgo nomeou como "realpolitik"3 (GAGO, 2020, p. 188).

Em "\#LalnternacionalFeminista", o movimento é apresentado como um fenômeno mundial (GAGO, 2020, p. 217). Esse transnacionalismo resvala em uma ubiquidade responsável por conectar constelações de lutas por meio da mobilização de corpos-territórios, sendo eles sobretudo os territórios domésticos, indígenas e da precarização. Eles se entrelaçam, produzindo uma "ubiquidade sem homogeneidade" por meio da qual se tem um "corpo comum, antes que uma estrutura" (GAGO, 2020, p. 224). E foi

por isso [que] a greve feminista permitiu repensar, requalificar e relançar outro sentido de greve geral. A tese seria, portanto, que a greve geral se torna realmente geral quando feminista. Porque assim, pela primeira vez, alcança todos os espaços, tarefas e formas de trabalho, conseguindo arraigar-se e territorializar-se sem deixar nada fora, produzindo então generalidade (GAGO, 2020, p. 229).

\footnotetext{
${ }^{2}$ Verónica Gago defende que "as assembleias funcionam como cozinha porque nelas se elabora um diagnóstico feminista da crise que faz com que seja uma fórmula prática e um mapeamento efetivo [...]" (GAGO, 2020, p. 189). ${ }^{3}$ Trata-se de "um modo de enlaçar as transformações cotidianas com o horizonte de transformação radial, em um movimento aqui e agora, de mútua imbricação" (GAGO, 2020, p. 205).
} 
A contraofensiva engatilhada pela radicalização do movimento feminista é tema do sétimo capítulo, "Contraofensiva: o espectro do feminismo". Nele, mapeiam-se três iniciativas: a contraofensiva eclesiástica, a contraofensiva moral e econômica e a contraofensiva militar. A primeira é abordada problematizando o conceito "ideologia de gênero" pelo mapeamento das lutas pelo direito ao aborto. A segunda contraofensiva - moral e econômica - acontece pela via de querelas em torno da definição de neoliberalismo, sendo lida como um terror financeiro já que engatilha uma contrarrevolução cotidiana ao unificar a moralidade devedora e a moralidade familiarista (GAGO, 2020, p. 270).

Por fim, a contraofensiva militar se faz ver pelo cruzamento de violências estatais e institucionais e por suas dinâmicas repressivas paraestatais, amalgamando estratégias de disciplinamento lado a lado com o terror financeiro. Para tanto, cita o exemplo do fascismo como política que constrói um inimigo interno na "tentativa de estabilizar a contínua crise de legitimidade política do neoliberalismo" (GAGO, 2020, p. 272).

O livro encerra com dois apêndices. O primeiro deles - "Oito teses sobre revolução feminista" - reelabora os capítulos que o precederam em uma estrutura de tópicos, retomando os principais pontos de discussão. O segundo se trata de um trecho de entrevista concedida pela autora a Roxana Sandá, publicada originalmente em 2019. Vale também destacar que cada um dos capítulos é acompanhado de uma "digressão" por meio da qual Verónica Gago reelabora o tópico discutido tangenciando-o com experiências de militância de diversos países.

Trata-se, portanto, de um livro-manifesto que se ocupa de elaborações teóricas sobre a militância recente dos feminismos. Traz a marca de uma escrita engajada tanto pelos assuntos discutidos quanto pela constante interpelação teórica dos movimentos de rua. A esse respeito, tem a marca do perfil de engajamento da autora e ilustra o deslizamento das discussões acadêmicas em direção a demandas socialmente alavancadas. Contribui, portanto, para as discussões a respeito das pautas feministas ao cartografar as contribuições do movimento nas elaborações sobre as greves, violências e engajamentos.

\section{Referência}

GAGO, Verónica. A potência feminista ou o desejo de transformar tudo. Trad. de Igor Peres. São Paulo: Elefante, 2020.

Carolina Cechella Philippi (carolinacechella@gmail.com) é historiadora formada pela Universidade Federal de Santa Catarina e pedagoga pela Universidade do Estado de Santa Catarina. É doutora em Educação pela Faculdade de Educação da Universidade Estadual de Campinas. Seus principais temas de estudo são História da Educação, Burocracia e Políticas Educacionais. 
COMO CITAR ESTE ARTIGO DE ACORDO COM AS NORMAS DA REVISTA

PHILIPPI, Carolina Cechella. "Cartografias militantes". Revista Estudos Feministas, Florianópolis, v. 30, n. 1, e77186, 2022

\section{CONTRIBUIÇĀO DE AUTORIA}

Não se aplica.

\section{FINANCIAMENTO}

Não se aplica.

\section{CONSENTIMENTO DE USO DE IMAGEM}

Não se aplica.

\section{APROVAÇĀO DE COMITÊ DE ÉTICA EM PESQUISA}

Não se aplica.

\section{CONFLITO DE INTERESSES}

Não se aplica.

\section{LICENÇA DE USO}

Este artigo está licenciado sob a Licença Creative Commons CC-BY 4.0 International. Com essa licença você pode compartilhar, adaptar, criar para qualquer fim, desde que atribua a autoria da obra.

\section{HISTÓRICO}

Recebida em 16/09/2020

Aceita em 12/10/2020 